\title{
Laboratory-based surveillance of current antimicrobial resistance patterns and trends among Staphylococcus aureus: 2005 status in the United States
}

\author{
David Styers $^{\dagger 1}$, Daniel J Sheehan ${ }^{\dagger 2}$, Patricia Hogan ${ }^{\dagger 2}$ and Daniel F Sahm*†1
}

Address: ${ }^{1}$ Focus Bio-Inova, Inc., 13665 Dulles Technology Drive, Herndon, VA 20171, USA and 2Pfizer, Inc, Pfizer Global Pharmaceuticals, 234 E. 42nd Street, New York, N.Y. 10017, USA

Email: David Styers - dstyers@focusbioinova.com; Daniel J Sheehan - sheehd@pfizer.com; Patricia Hogan - hoganp@pfizer.com; Daniel

F Sahm* - dsahm@focusbioinova.com

* Corresponding author †Equal contributors

Published: 09 February 2006

Annals of Clinical Microbiology and Antimicrobials 2006, 5:2 doi:10.1 I86/I476-07। I-5-2

This article is available from: http://www.ann-clinmicrob.com/content/5/I/2

(C) 2006 Styers et al; licensee BioMed Central Ltd.

This is an Open Access article distributed under the terms of the Creative Commons Attribution License (http://creativecommons.org/licenses/by/2.0), which permits unrestricted use, distribution, and reproduction in any medium, provided the original work is properly cited.
Received: 26 September 2005

Accepted: 09 February 2006

\begin{abstract}
Background: The virulence, antimicrobial resistance, and prevalence of S. aureus underscores the need for up-to-date and extensive insights regarding antimicrobial susceptibility trends. One approach to meet this need is analysis of clinical laboratory - based surveillance data.

Methods: Data from The Surveillance Network-USA (TSN), an electronic surveillance network that collects microbiology data from 300 clinical microbiology laboratories across the United States, were used as the source for analysis that included prevalence of $S$. aureus in clinical specimens, MRSA and multi-drug resistance phenotype rates and trends according to patient location, geographic distributions, and specimen source.
\end{abstract}

Results: S. aureus was the most prevalent species isolated from inpatient specimens (18.7\% of all bacterial isolates) and the second most prevalent (14.7\%) from outpatient specimens. In March 2005 MRSA rates were $59.2 \%, 55 \%$, and $47.9 \%$ for strains from non-ICU inpatients, ICU, and outpatients, respectively. This trend was noted in all nine US Bureau of Census regions and multidrug resistance phenotypes (resistance to $\geq 3$ non-beta-lactams) was common among both inpatient MRSA (59.9\%) and outpatient MRSA (40.8\%). Greater than $90 \%$ of multi-drug resistant MRSA were susceptible to trimethoprim-sulfamethoxazole, linezolid, and vancomycin.

Conclusion: Prevalence of MRSA among both inpatient and outpatient specimens continues to increase with multi-drug resistance as a common phenotype. Continued emergence of outpatient MRSA that exhibit multi-drug resistant phenotypes has important implications for developing and evolving outpatient treatment guidelines.

\section{Background}

Staphylococcus aureus exhibits three problematic features that, taken together, are not found among most other clinically relevant bacteria. This species is capable of expressing a variety of virulence factors and thus is almost always considered medically relevant when encountered in clinical specimens; the organism continues to demonstrate the ability to develop and expand resistance to include a broad array of antimicrobial classes, and S. aureus is a prominent pathogen in both the hospital and the com- 


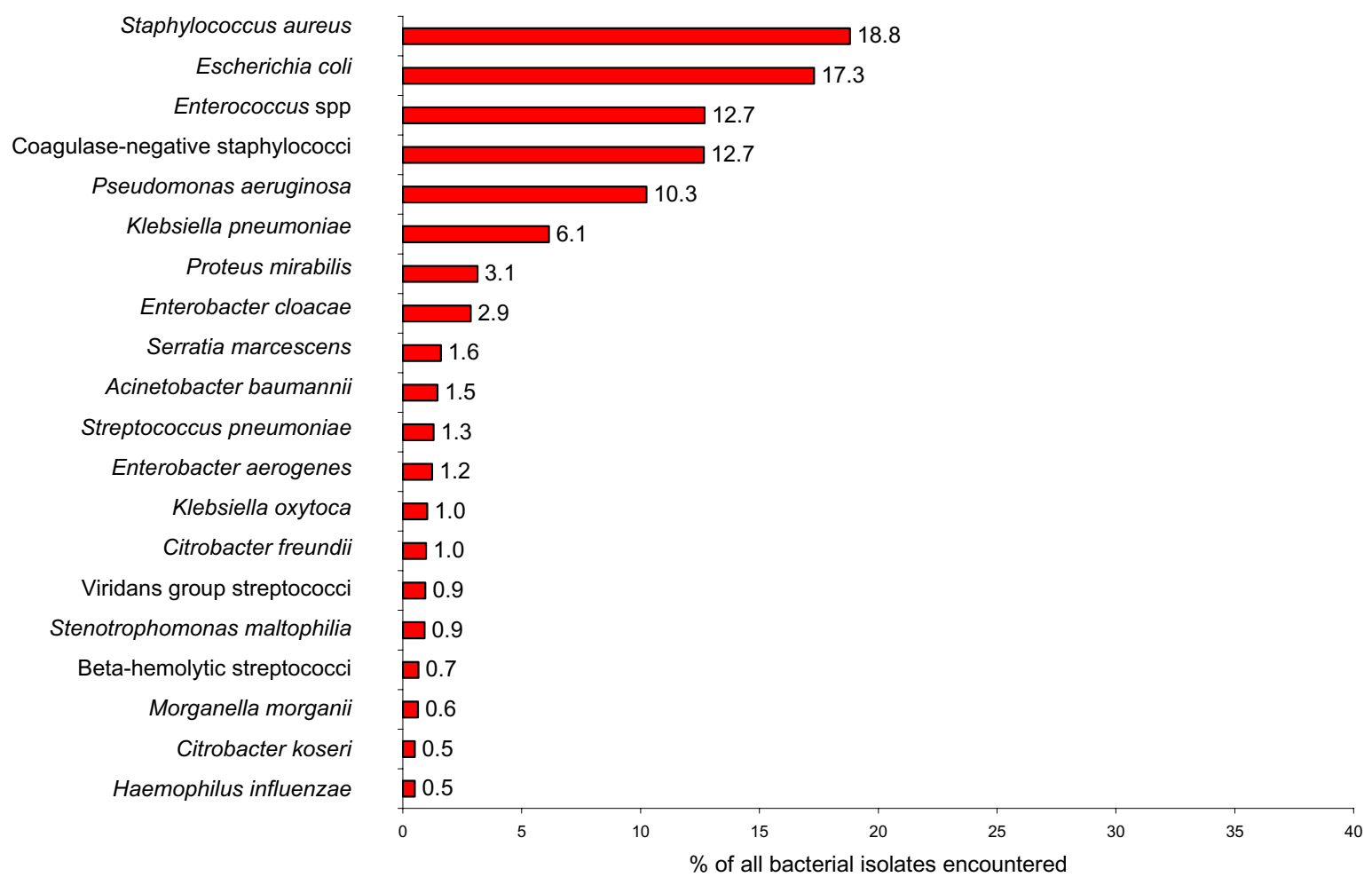

Figure I

Relative frequency of bacterial species/groups encountered in clinical specimens from inpatients. Data is cumulative data: 1998 - March 2005 and based on a total of 3,209,4I3 bacterial isolates.

munity settings $[1,2]$. This combination of characteristics underscores the need to monitor and report $S$. aureus trends and patterns in a timely and thorough manner, especially with regard to antimicrobial susceptibility profiles and the clinical settings in which the organism is encountered.

To gain more extensive insights regarding recent antimicrobial trends among S. aureus, analysis of strain data obtained from geographically and demographically diverse patient populations in the United States is necessary. One approach that can provide key information in this regard involves the application of laboratory - based surveillance. Analysis of microbiology data generated in support of patient care by clinical laboratories across the United States has been used in the past to provide perspective on a variety of antimicrobial resistance trends among key bacterial pathogens [3-6]. Further, Fridkin et al [7] have reported that laboratory derived antimicrobial data can provide reliable perspectives on resistance rates among patients with hospital - acquired infections.
Therefore, to help meet the need for current and broadbased information regarding $S$. aureus trends, data obtained through The Surveillance Network-USA (TSN) were analyzed for resistance trends overall and in both the inpatient and outpatient settings.

\section{Methods}

The Surveillance Network (TSN) was the data source used for this investigation and analysis. TSN is an electronic database of strain specific, qualitative and quantitative antimicrobial susceptibility test data reported by clinical laboratories in North America that has been used extensively in the past to evaluate various trends regarding antimicrobial susceptibility [3-6]. At the time of this analysis TSN contained more than 105 million susceptibility test results overall that were gathered from 300 USA hospitals distributed across the United States. In addition to antimicrobial susceptibility profiles other query parameters that may be used individually or in any combination for analysis of antimicrobial susceptibility data include organism identification, national and regional geography (i.e. the 


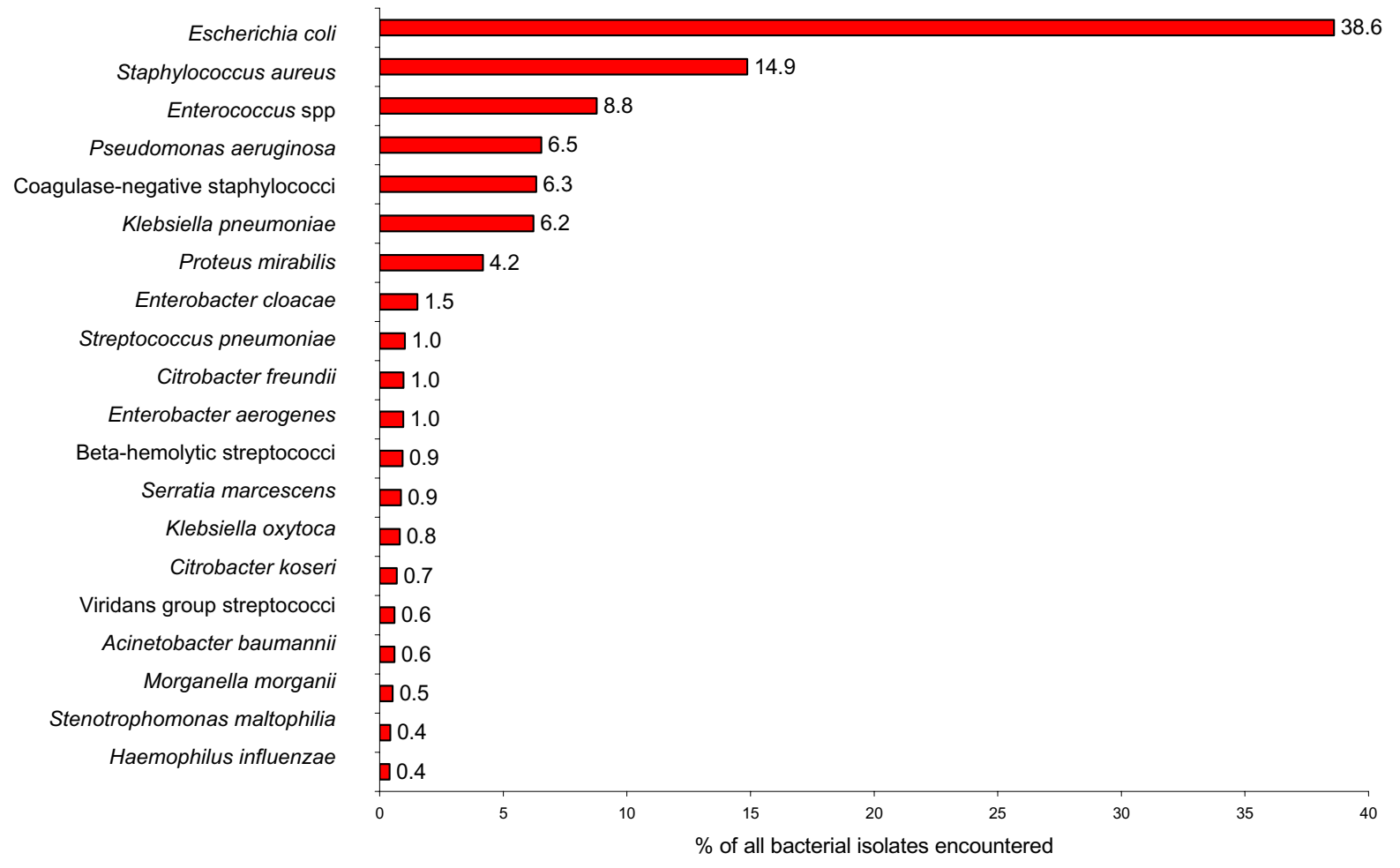

\section{Figure 2}

Relative frequency of bacterial species/groups encountered in clinical specimens from outpatients. Data is cumulative data: 1998 - March 2005 and based on a total of 3,209,4I3 bacterial isolates.

nine regions of the US Census Bureau), institution demographics (type, number of beds), patient demographics (age, gender, and location), and specimen source.

This study focused specifically on $S$. aureus and used TSN data collected from 1998 to March 2005. The overall prevalence of $S$. aureus isolated from inpatient and outpatient specimens was calculated by using all organism groups and species isolated from each patient group as the denominator. MRSA rates for the study period were examined overall and according to three patient location categories as designated by each laboratory's information system (outpatient, inpatient [non-ICU], and ICU). The outpatient designation indicates that the specimen submitted for culture was obtained from patients seen in an outpatient setting. For all patient locations three categories of clinical specimen source were analyzed and included lower respiratory tract, skin and soft tissue (included wounds), and blood. Multi-drug resistance for MRSA was defined as resistance to three or more agents among ciprofloxacin, erythromycin, clindamycin, gentamicin, trimethoprim/sulfamethoxazole, linezolid, and vancomycin. Only strains tested simultaneously against all of these agents were included in the multi-drug resistance analysis of prevalence and distribution of resistance phenotypes.

\section{Results}

The top 20 most commonly reported bacterial species or organism groups isolated from inpatient and outpatients, as reported by clinical laboratories throughout the United States from 1998 to 2005, are shown in Figures 1 and 2, respectively. For both inpatient and outpatient specimens, $S$. aureus and E. coli were the two most common species reported. Among inpatients, $S$. aureus was more prominent $(18.7 \%)$ than E. coli $(17.3 \%)$. For outpatient specimens the reverse was noted; E. coli $(38.6 \%)$ and $S$. aureus $(14.7 \%)$. The relative incidence of $S$. aureus among all reported organisms was similar for inpatients $(18.7 \%)$ and outpatients (14.7\%).

With regard to resistance trends, overall MRSA rates have steadily increased in the USA since 1998 and the rate appeared to be still on the rise as of March, 2005 (53.3\%: 


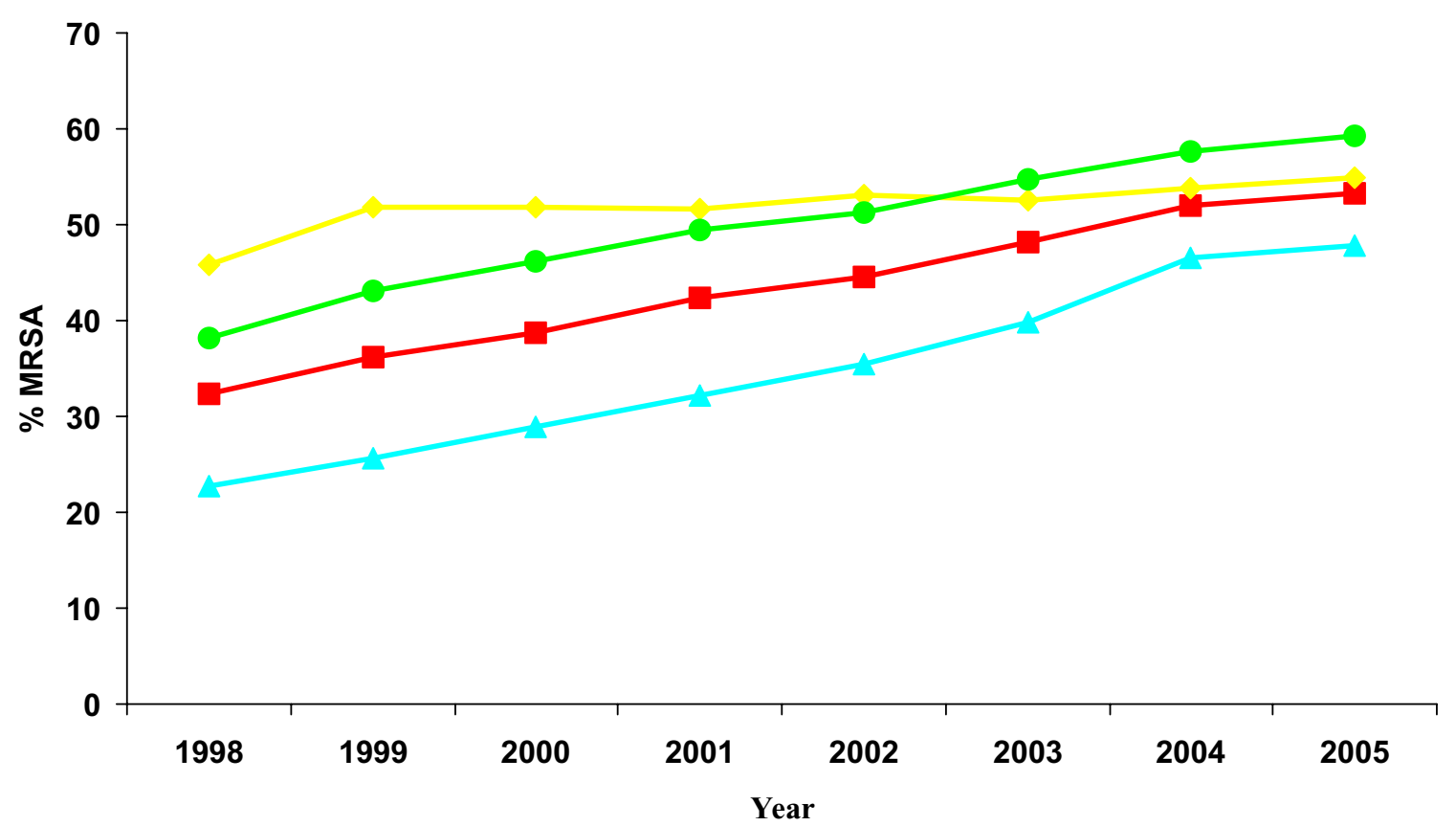

\section{Figure 3}

MRSA trends (1998 - YTD 2005) according to patient location. Data is cumulative data: 1998 - March 2005. Red line, all patients; yellow line, ICU patients; green line, inpatients; blue line, outpatients.

Figure 3). An increase was noted among each patient group including strains from ICU patients, non-ICU inpatients, and outpatients with current MRSA rates of 55\%, $59.2 \%$, and $47.9 \%$, respectively. Since 2002 the lowest rate of increase in MRSA occurred among specimens from ICU patients while the rates among $S$. aureus from other inpatients and outpatients were higher.

Analysis of inpatient and outpatient MRSA rates according to geographic distribution demonstrated that trends for MRSA have occurred in each of the nine regions of the US Census Bureau (Figure 4). In all regions, except New England, inpatient MRSA rates were above 50\%. The lowest outpatient MRSA rates occurred in the Mid Atlantic (36.3\%) and New England (37.6\%) regions; while the highest rate $(63 \%)$ occurred in the East South Central region where inpatient and outpatient MRSA rates were the same.

According to specimen source, MRSA rates were highest (55.9\%) among strains from inpatient lower respiratory specimens and lowest (37.6\%) among strains from outpatient skin and soft tissue specimens (Table 1). For both inpatients and outpatients the range of MRSA rates according to specimen source was relatively narrow, 48.6 - 55.9\% and 37.6 - 42.8\%, respectively. Approximately

Table I: MRSA rates among inpatients and outpatients by specimen source ${ }^{a}$

\begin{tabular}{|c|c|c|c|c|}
\hline \multirow[b]{2}{*}{ Specimen Source } & \multicolumn{2}{|c|}{ Inpatient } & \multicolumn{2}{|c|}{ Outpatient } \\
\hline & Total $\mathrm{N}$ & (\%) MRSA & Total N & (\%) MRSA \\
\hline Lower Respiratory Tract & 188,939 & (55.9) & 51,057 & (42.8) \\
\hline Skin and Soft Tissue & 61,099 & $(48.6)$ & 56,830 & (37.6) \\
\hline Blood & 92,694 & $(49.1)$ & 31,886 & (4I.4) \\
\hline
\end{tabular}

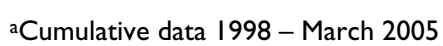




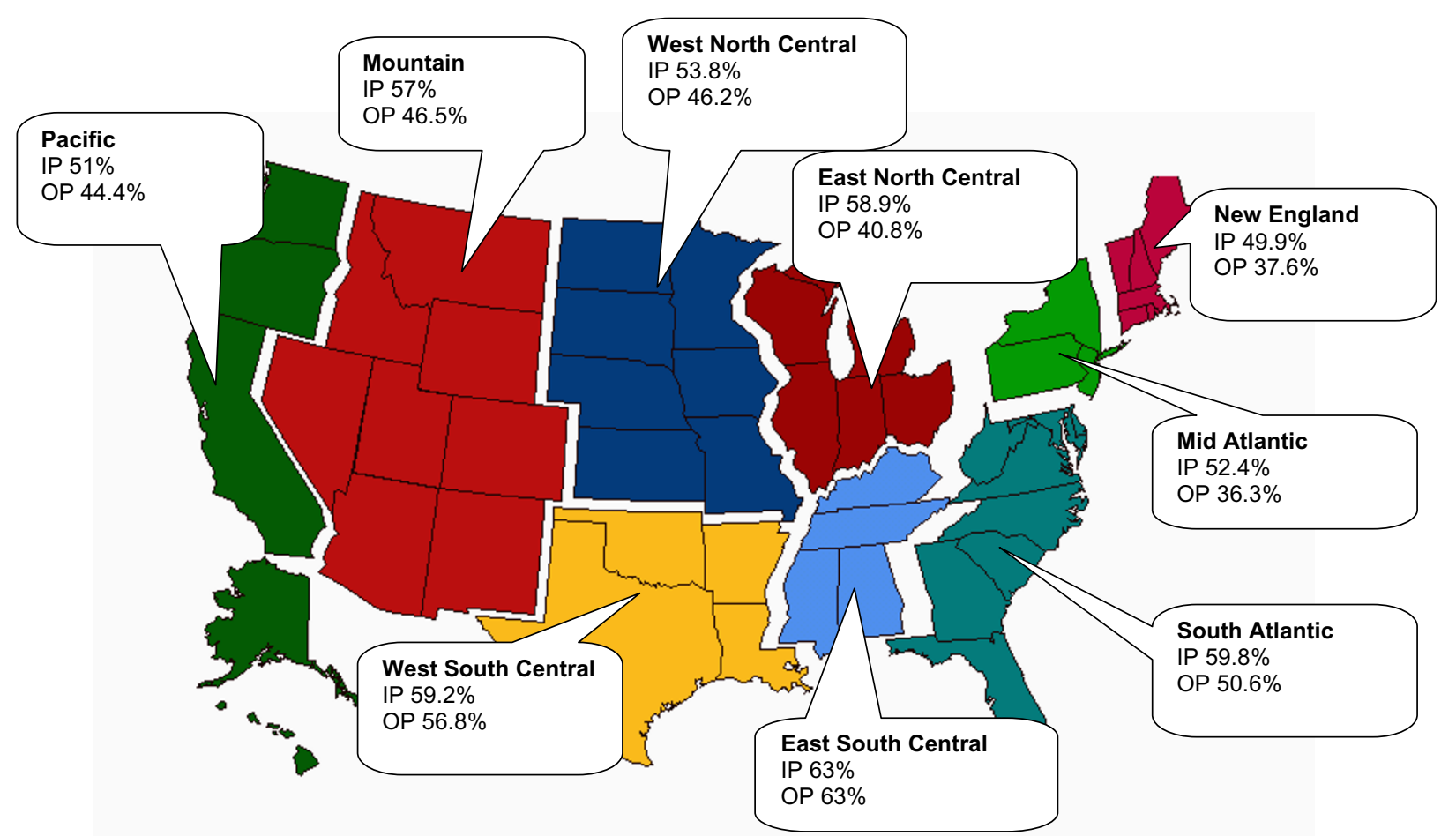

\section{Figure 4}

Inpatient (IP) and outpatient (OP) MRSA rates according to US Census Bureau Regions. Data is cumulative data: 1998 - March 2005.

$41 \%$ of $S$. aureus strains obtained from 31,886 blood cultures taken in the outpatient setting were MRSA.

Regardless of the specimen source, the multi-drug resistance rates among MRSA were higher among inpatient strains than among outpatient strains (Table 2). For both inpatient and outpatient MRSA, the highest multi-drug resistance rates occurred among lower respiratory tract isolates (67.8\% for inpatients; $65 \%$ for outpatients) and the lowest rates were among skin and soft tissue specimens (35.8\% for inpatients; $22.2 \%$ for outpatients).

For outpatient and inpatient MRSA combined, 29 different resistance phenotypes were noted, 24 of which occurred in both populations (Table 3 ). The spectrum of phenotypes ranged from susceptibility to all non-betalactams to resistance to five of the seven non-beta-lactams included in the multi-drug resistance analysis. Resistance to vancomycin was not encountered and non-susceptibil-

Table 2: Multi-drug resistance (MDR)a rates among MRSA from inpatients and outpatients by specimen source ${ }^{b}$

\begin{tabular}{|c|c|c|c|c|}
\hline \multirow[b]{2}{*}{ Specimen Source } & \multicolumn{2}{|c|}{ Inpatient } & \multicolumn{2}{|c|}{ Outpatient } \\
\hline & Total $\mathrm{N}$ & (\%) MDR & Total $\mathrm{N}$ & (\%) MDR \\
\hline Lower Respiratory Tract & 5,134 & $(67.8)$ & 1,136 & $(65.0)$ \\
\hline Skin and Soft Tissue & 2,122 & (35.8) & 2,275 & $(22.2)$ \\
\hline Blood & 3,064 & $(63.3)$ & 904 & $(56.7)$ \\
\hline
\end{tabular}

a Multiple-drug resistance (MDR): resistance to three or more of the following agents: ciprofloxacin, erythromycin, clindamycin, gentamicin, trimethoprim/sulfamethoxazole, linezolid, and vancomycin

bCumulative data 1998 - March 2005 
Table 3: Distribution of resistance phenotypes ${ }^{\mathrm{a}}$ among inpatient and outpatient MRSA

\begin{tabular}{|c|c|c|c|c|c|}
\hline \multirow[b]{2}{*}{ Category } & \multirow[b]{2}{*}{ Resistance phenotype } & \multicolumn{2}{|c|}{ Inpatient } & \multicolumn{2}{|c|}{ Outpatient } \\
\hline & & $\mathrm{n}$ & (\%) & $\mathrm{n}$ & (\%) \\
\hline Susceptible to all other agents & - & 418 & $(4.1)$ & 245 & (5.7) \\
\hline \multirow[t]{4}{*}{ Single-drug resistant } & Eryth & 1409 & $(13.7)$ & 1200 & $(27.8)$ \\
\hline & Cipro & 232 & $(2.2)$ & 92 & $(2.1)$ \\
\hline & Gent & 8 & $(0.1)$ & 3 & $(0.1)$ \\
\hline & Clinda & 4 & $(0.0)^{c}$ & 5 & $(0.1)$ \\
\hline \multirow[t]{8}{*}{ Double-drug resistant } & Cipro, Eryth & 1854 & $(18.0)$ & 870 & $(20.2)$ \\
\hline & Eryth, Clinda & 114 & $(I .1)$ & 104 & $(2.4)$ \\
\hline & Cipro, Clinda & 62 & $(0.6)$ & 23 & $(0.5)$ \\
\hline & Cipro, Gent & 8 & $(0.1)$ & 12 & $(0.3)$ \\
\hline & Cipro, SXT & 14 & $(0.1)$ & 2 & $(0.0)^{c}$ \\
\hline & Eryth, SXT & 2 & $(0.0)^{c}$ & I & $(0.0)^{c}$ \\
\hline & Eryth, Gent & 10 & $(0.1)$ & 1 & $(0.0)^{c}$ \\
\hline & Gent, SXT & 2 & $(0.0)^{c}$ & 0 & $(0.0)$ \\
\hline \multirow[t]{17}{*}{ Multidrug-resistant } & Cipro, Eryth, Clinda & 4915 & $(47.6)$ & 1417 & (32.8) \\
\hline & Cipro, Eryth, Gent & 30 & $(0.3)$ & 18 & $(0.4)$ \\
\hline & Cipro, Eryth, SXT & 23 & $(0.2)$ & 7 & $(0.2)$ \\
\hline & Cipro, Gent, SXT & 18 & $(0.2)$ & 10 & $(0.2)$ \\
\hline & Eryth, Clinda, Gent & 5 & $(0.0)$ & 5 & $(0.1)$ \\
\hline & Cipro, Clinda, Gent & 6 & $(0.1)$ & 3 & $(0.1)$ \\
\hline & Eryth, Clinda, SXT & 2 & $(0.0)^{c}$ & I & $(0.0)^{c}$ \\
\hline & Eryth, Gent, SXT & 0 & $(0.0)$ & 1 & $(0.0)^{c}$ \\
\hline & Cipro, Clinda, SXT & 2 & $(0.0)^{c}$ & 0 & $(0.0)$ \\
\hline & Cipro, Eryth, Lin & 3 & $(0.0)^{c}$ & 0 & $(0.0)$ \\
\hline & Cipro, Eryth, Clinda, Gent & 858 & $(8.3)$ & 214 & $(5.0)$ \\
\hline & Cipro, Eryth, Clinda, SXT & 58 & $(0.6)$ & 14 & $(0.3)$ \\
\hline & Cipro, Eryth, Gent, SXT & 12 & $(0.1)$ & 4 & $(0.1)$ \\
\hline & Eryth, Clinda, Gent, SXT & 2 & $(0.0)^{c}$ & 0 & $(0.0)$ \\
\hline & Cipro, Clinda, Gent, SXT & 2 & $(0.0)^{c}$ & 0 & $(0.0)$ \\
\hline & Cipro, Eryth, Clinda, Gent, SXT & 247 & $(2.4)$ & 63 & ( 1.5$)$ \\
\hline & Total n & 10,320 & & 4,315 & \\
\hline
\end{tabular}

${ }^{a}$ Analysis included the following agents: gentamicin (Gent), erythromycin (Eryth), clindamycin (Clinda), trimethoprim-sulfamethoxazole (SXT), ciprofloxacin (Cipro), vancomycin (Vanc), and linezolid (Lin). Multi-drug resistance included resistance to three or more of the agents listed. bCumulative data 2002 - March 2005

$c_{n}<0.1 \%$ of total

ity to linezolid occurred with three of 14,635 MRSA strains $(0.02 \%)$ profiled in this analysis. Susceptibility to all non-beta-lactams studied was more common among outpatient MRSA (5.7\%) than among inpatient MRSA (4.1\%), but the frequencies of the susceptible phenotype were comparable between MRSA strains from these two patient populations.

The most common resistance phenotypes among inpatient MRSA were multi-drug resistance to ciprofloxacin, erythromycin, and clindamycin $(47.6 \%)$, double drug resistance to ciprofloxacin and erythromycin (18\%), single drug resistance to erythromycin (13.7\%), and multidrug resistance to ciprofloxacin, erythromycin, clindamycin, and gentamicin (8.3\%) (Table 3). Among outpatient MRSA single drug resistance to erythromycin $(27.8 \%)$ was the most common phenotype followed by multi-drug resistance to ciprofloxacin, erythromycin, and clindamycin $(32.8 \%)$, and dual resistance to ciprofloxacin and erythromycin $(20.2 \%)$. In all, $11.4 \%(n=1,179)$ of inpatient MRSA were resistant to four or more non-betalactam agents and $2.4 \%(\mathrm{n}=247)$ were resistant to five agents. In comparison, $6.8 \%(\mathrm{n}=295)$ of outpatient MRSA were resistant to four or more non-beta-lactams and $1.5 \%(\mathrm{n}=63)$ were resistant to five agents.

For both outpatient and inpatient multi-drug resistant MRSA the only agents with $>90 \%$ susceptibility were trimethoprim/sulfamethoxazole, linezolid, and vancomycin (Table 4). This same hierarchy of antimicrobial activity was maintained when data were analyzed according to clinical specimen source (data not shown). The > 
Table 4: Antibiograms of multi-drug resistant ${ }^{a}$ MRSA from inpatients and outpatients ${ }^{b}$

\begin{tabular}{|c|c|c|c|c|}
\hline \multirow[b]{2}{*}{ Agents } & \multicolumn{2}{|c|}{ Inpatient $(n=6,183)$} & \multicolumn{2}{|c|}{ Outpatient $(n=1,757)$} \\
\hline & $\mathrm{n}$ & (\%) Susceptible & $\mathrm{n}$ & (\%) Susceptible \\
\hline Ciprofloxacin & 7 & $(0.1)$ & 5 & $(0.3)$ \\
\hline Erythromycin & 20 & $(0.3)$ & 13 & $(0.7)$ \\
\hline Clindamycin & 85 & ( $(1.4)$ & 38 & $(2.2)$ \\
\hline Gentamicin & 4,971 & $(80.4)$ & 1,430 & $(81.4)$ \\
\hline Trimethoprim-sulfamethoxazole & 5,814 & $(94.0)$ & 1,657 & $(94.3)$ \\
\hline Linezolid & 6,180 & $(>99.9)$ & 1,757 & $(100)$ \\
\hline Vancomycin & 6,183 & $(100.0)$ & $\mathrm{I}, 757$ & $(100)$ \\
\hline
\end{tabular}

Multiple-drug resistance: resistance to three or more of the following agents: ciprofloxacin, erythromycin, clindamycin, gentamicin, trimethoprim/ sulfamethoxazole, linezolid, and vancomycin

bCumulative data 1998 - 2005 YTD

99.9\% linezolid susceptibility for inpatient MRSA strains resulted from three of 6,183 strains being reported as nonsusceptible.

\section{Discussion and conclusion}

This analysis of data obtained through clinical laboratory based surveillance has demonstrated that $S$. aureus continues to be solidly positioned as a leading bacterial pathogen encountered in both inpatient and outpatient clinical settings and has continued to substantially outdistance other gram-positive organisms in this regard. Because most clinical microbiology protocols call for $S$. aureus to be "worked-up" and reported regardless of the amount of organisms present, or the type of specimen, there is a likelihood that the reporting frequency based on laboratory data is higher than the actual frequency of infections caused by this organism. Nonetheless, the same bias plays a role for many other reported bacterial species so that the position of $S$. aureus as the leading gram-positive organism, and its frequency relative to other species, is likely quite reflective of actual infection rates as well. The high prevalence of $S$. aureus reported here for both the inpatient and outpatient environments was consistent with recent descriptions and discussion regarding the changing epidemiology of this organism $[1,2]$.

The high prevalence of $S$. aureus in both settings underscores the need for analysis of antimicrobial resistance trends according to patient location so that variations in antimicrobial resistance trends among strains from patients seen in the different clinical settings can be evaluated. Although previous surveillance initiatives that included $S$. aureus have involved isolates from both outpatients and inpatients, they examined strains collected prior to 2002 and a thorough comparison of the resistance rates and phenotypes according to patient location were not reported $[8,9]$. In this current study antimicrobial data from geographically, demographically, and clinically diverse settings, collected via The Surveillance
Network, were analyzed to provide a clearer and current perspective on the resistance profiles currently present among $S$. aureus in the United States.

The data provided in Figure 3 demonstrated that MRSA rates continue to be on the rise among both inpatients and outpatients, and this trend appeared to be pervasive throughout all regions of the United States (Figure 4). Rising rates of MRSA in the hospital environment were reported from studies done in previous years and data presented here indicate that the increasing rates have continued into 2005 [7,10-12]. The relatively lower increase in MRSA observed here among ICU S. aureus is consistent with the most recent report from the National Nosocomial Infections Surveillance (NNIS) System Report [12]. Although the rate increase may be relatively lower than before, the overall prevalence of MRSA in the ICU remains high (55\%).

In addition to the issue of increasing MRSA rates among inpatients, the recognized emergence of MRSA beyond the hospital or healthcare setting into the community has raised another substantial public health concern about $S$. aureus [2,13-17]. Based on this current laboratory - based surveillance study the concern is much warranted as outpatient MRSA rates have continued to increase to the extent that as of 2005 the overall MRSA rate in this population was $47.9 \%$ (Figure 3). Further, the data in Table 1 indicated that MRSA are commonly isolated from all types of outpatient specimens, including blood.

MRSA that are encountered in the community (outpatient settings) arise either as a result of acquisition of the mec gene complex by susceptible $S$. aureus strains (so-called de novo community MRSA), or by person-to-person carriage of hospital strains into the community $[2,18]$. No phenotypic or genotypic criteria have been firmly established to definitively specify a strain as being from one or the other origin; this requires rigorous and diligent epidemiological 
analysis. However, de novo MRSA have generally been characterized as being susceptible to most non-betalactam agents (other than erythromycin) while those that have spread from the hospital setting into the community often exhibit the multi-drug resistant phenotype that is characteristic of most hospital-based strains $[2,13,18,19]$.

The significant contrast in MRSA resistance phenotypes that may exist depending on the origin of a community strain (i.e. hospital or de novo) can confound empiric therapeutic decisions when patients suspected of being infected with $S$. aureus are initially evaluated in the outpatient setting. While the rates of multi-drug resistant phenotypes among inpatient MRSA were higher than those among outpatient MRSA, multi-drug resistance was a common feature among the community outpatient population (Table 2). In addition, there was substantial overlap in phenotypes between inpatient and outpatient MRSA (Table 3). These findings, based on data from across the USA collected since 1998, indicate that strains of hospital origin constitute the majority of MRSA encountered in the outpatient setting. This is consistent with the local findings reported by Charlebois et al. [18] in which a substantial proportion of outpatient MRSA had resistance profiles comparable to those of the hospital-based strains. Their analysis led the authors to suggest that most of the community MRSA strains from the area studied around San Francisco were likely descendants of hospital origin. Further, a previous study we conducted also strongly suggested that community MRSA frequently emerge from the local hospital populations [4].

For multi-drug resistant inpatient and outpatient MRSA alike there are relatively few agents that maintained high levels of activity (Table 4). This situation combined with the propensity of certain community clones to exhibit substantial virulence with elaboration of toxins such as Panton-Valentine Leuckocidin (PVL) raises concern about future therapeutic guidelines for $S$. aureus infections encountered in the outpatient settings [20-22].

The most common multi-drug resistant phenotype encountered would preclude the use of all current betalactams, clindamycin, macrolides, and fluoroquinolones against outpatient MRSA. Although clindamycin is frequently considered for infections in this setting, over $30 \%$ of outpatient MRSA were resistant. The agents that consistently demonstrated high levels of activity against outpatient MRSA, including strains exhibiting the multi-drug resistant phenotype, were trimethoprim/sulfamethoxazole, linezolid, and vancomycin. No resistance to either vancomycin or linezolid was encountered among outpatient MRSA, including multi-drug resistant strains. Therefore, while there have been reports of resistance to these two agents, resistance remains sporadic and extremely rare
$[1,23]$. Because resistance to either vancomycin or linezolid is extremely rare among all $S$. aureus, use of either agent is not likely to lead to expansion of multi-drug resistant clones as could result from use of the other agents to which $S$. aureus populations have already developed resistance. However, with regard to vancomycin, the lack of an oral formulation with absorption introduces a limitation as an option for the management of outpatient MRSA infections. Linezolid has exhibited successful activity relative to vancomycin for MRSA and is available as an oral formulation [24-26].

The continued increase in MRSA rates among inpatient specimens coupled with the emergence of MRSA in the community (outpatient) setting has involved strains that frequently exhibit multiple drug resistance. For some time these resistance phenotypes have been an issue for the management of inpatients. Now current trends indicate there are important implications for establishing outpatient management and treatment guidelines for staphylococcal infections. Given this trend, health care institutions should consider analyzing their local S. aureus antibiograms according to outpatient and inpatient populations in order to discern the prevalent phenotypes physicians are likely to encounter in each setting. Finally, if the current trend continues, the development of new anti-MRSA agents for multi-drug resistant strains will have to consider the need for both community and hospital use.

\section{Authors' contributions}

Conception and design: P Hogan, DJ Sheehan, DF Sahm.

Assembly of data and analysis: D Styers, DF Sahm.

Drafting of the article: P Hogan, DJ Sheehan, DF Sahm.

\section{Acknowledgements}

This study was funded by Pfizer Inc, Pfizer Global Pharmaceuticals, New York, New York.

\section{References}

I. Deresinski S: Methicillin-resistant Staphylococcus aureus: an evolutionary, epidemiologic, and therapeutic odyssey. Clin Infect Dis 2005, 40:562-573.

2. Chambers HF: The changing epidemiology of Staphylococcus aureus? Emerg Infect Dis 200I, 7:178-82.

3. Sahm DF, Marsilio MK, Piazza G: Antimicrobial resistance in key bloodstream bacterial isolates: electronic surveillance with The Surveillance Network Database - USA. Clin Infect Dis 1999, 29:259-63.

4. Jones ME, Mayfield DC, Thornsberry C, Karlowsky JA, Sahm DF, Peterson D: Prevalence of oxacillin resistance in Staphylococcus aureus among inpatients and outpatients in the United States during 2000. Antimicrob Agents Chemother 2002, 46:3104-5.

5. Karlowsky JA, Draghi DC, Jones ME, Thornsberry C, Friedland IR, Sahm DF: Surveillance for antimicrobial susceptibility among clinical isolates of Pseudomonas aeruginosa and Acinetobacter baumannii from hospitalized patients in the United States, 1998 to 200 I. Antimicrob Agents Chemother 2003, 47:168I-88.

6. Flamm RK, Weaver MK, Thornsberry C, Jones ME, Karlowsky JA, Sahm DF: Factors associated with relative rates of antibiotic 
resistance in Pseudomonas aeruginosa isolates tested in clinical laboratories in the United States from 1999 to 2002. Antimicrob Agents Chemother 2004, 48:243I-6.

7. Fridkin SK, Edwards JR, Tenover FC, et al.: Antimicrobial resistance prevalence rates in hospital antibiograms reflect prevalence rates among pathogens associated with hospitalacquired infections. Clin Infect Dis 200I, 33:324-30.

8. Critchley IA, Blosser-Middleton RS, Jones ME, Thornsberry C, Sahm DF, Karlowsky JA: Baseline study to determine in vitro activities of daptomycin against gram-positive pathogens isolated in the United States in 2000-200 I. Antimicrob Agents Chemother 2003, 47: 1689-1693.

9. Diekema DJ, Pfaller MA, Schmitz FJ, et al.: Survey of infections due to Staphylococcus species: frequency of occurrence and antimicrobial susceptibility of isolates collected in the United States, Canada, Latin America, Europe, and the Western Pacific Region for the SENTRY Antimicrobial Surveillance Program, 1997-1999. Clin Infect Dis 200I, 32(Suppl 2):SII4-SI32.

10. Edmond MB, Wallace SE, McClish DK, Pfaller MA, Jones RN, Wenzel RP: Nosocomial bloodstream infections in United States hospitals: a three-year analysis. Clin Infect Dis 1999, 29:239-44.

II. Fridkin SK, Steward CD, Edwards JR, et al.: Surveillance of antimicrobial use and antimicrobial resistance in United States hospitals: project ICARE phase 2. Clin Infect Dis 1999, 29:245-52.

12. National Nosocomial Infections Surveillance System: National Nosocomial Infections Surveillance (NNIS) System Report, data summary from January 1992 through June issued August 2003. Am J Infect Control 2003, $31: 48 I-98$.

13. Eguia JM, Chambers HF: Community-acquired methicillin resistant Staphylococcus aureus: epidemiology and potential virulence factors. Curr Infect Dis Reports 2003, 5:459-66.

14. Mongkolrattanothai K, Boyle S, Kahana MD, Daum RS: Severe Staphylococcus aureus infections caused by clonally related community-acquired methicillin-susceptible and methicillinresistant isolates. Clin Infect Dis 2003, 37: 1050-58.

15. Naimi TS, LeDell KH, Como-Sabetti K, et al.: Comparison of community- and health care-associated methicillin-resistant Staphylococcus aureus infection. JAMA 2003, 290:2976-84.

16. Said-Salim B, Mathema B, Kreiswirth BN: Community-acquired methicillin-resistant Staphylococcus aureus: an emerging pathogen. Infect Control Hosp Epidemiol 2003, 24:45I-55.

17. Stemper ME, Shukla SK, Reed KD: Emergence and spread of community-associated methicillin-resistant Staphylococcus aureus in rural Wisconsin, 1989 to 1999. J Clin Microbiol 2004, 42:5673-80.

18. Charlebois ED, Perdreau-Remington F, Kreiswirth B, et al:: Origins of community strains of methicillin-resistant Staphylococcus aureus. Clin Infect Dis 2004, 39:47-54.

19. Tacconelli E, Venkataraman L, De Girolami PC, D'Agata EM: Methicillin-resistant Staphylococcus aureus bacteraemia diagnosed at hospital admission: distinguishing between communityacquired versus healthcare-associated strains. J Antimicrob Chemother 2004, 53:474-9.

20. Francis JS, Doherty MC, Lopatin U, et al.: Severe communityonset pneumonia in healthy adults caused by methicillinresistant Staphylococcus aureus carrying the Panoton-Valentine leuckocidin genes. Clin Infect Dis 2005, 40:100-107.

21. Lina G, Piemont Y, Godail-Gamot F, et al.: Involvement of PantonValentine Leukocidin-producing Staphylococcus aureus in primary skin infections and pneumonia. Clin Infect Dis 1999, 29: II 28-32.

22. Vandenesch F, Naimi T, Enright MC, et al:: Community-acquired methicillin-resistant Staphylococcus aureus carrying PantonValentine Leukocidin genes: worldwide emergence. Emerg Infect Dis 2003, 9:978-84.

23. Meka VG, Gold HS: Antimicrobial resistance to linezolid. Clin Infect Dis 2004, 39: 1010-15.

24. Stevens DL, Herr D, Lampiris $\mathrm{H}$, et al:: Linezolid versus vancomycin for the treatment of methicillin-resistant Staphylococcus aureus infections. Clin Infect Dis 2002, 34: I 48I-90.

25. Wargo KA, Eiland EH: Appropriate antimicrobial therapy for community-acquired methicillin-resistant Staphylococcus aureus carrying the Panton-Valentine Leukocidin genes. Clin Infect Dis 2005, 40:1376-8.
26. Wilcox M, Nathwani D, Dryden M: Linezolid compared with teicoplanin for the treatment of suspected or proven grampositive infections. J Antimicrob Chemother 2004, 53:335-44.
Publish with Bio Med Central and every scientist can read your work free of charge

"BioMed Central will be the most significant development for disseminating the results of biomedical research in our lifetime. "

Sir Paul Nurse, Cancer Research UK

Your research papers will be:

- available free of charge to the entire biomedical community

- peer reviewed and published immediately upon acceptance

- cited in PubMed and archived on PubMed Central

- yours - you keep the copyright

Submit your manuscript here:

http://www.biomedcentral.com/info/publishing_adv.asp
BioMedcentral 